\title{
El sistema ombudsman más caro del mundo... ¿y el más ineficiente? ${ }^{*}$
}

\section{Introducción}

Hace casi dos años, iniciamos un proyecto de investigación en el que nos propusimos analizar la construcción del campo de los defensores de los derechos humanos (DDH) en México, dado el grave dete-

El artículo analiza del campo de los defensores de derechos humanos en México, tomando en cuenta el rol que tiene el sistema ombudsman en cuanto a los asesinatos de defensores de derechos humanos en México. Se utilizan cinco indicadores para medir la eficiencia de las Comisiones Estatales y Nacional de Derechos Humanos: presupuesto, independencia, vínculo entre las quejas, recomendaciones y derecho vulnerado, relación entre las recomendaciones emitidas y las problemáticas sociales a nivel nacional y local, y finalmente, la relación entre las comisiones y las ONG.

Palabras clave: sistema ombudsman, derechos humanos, eficiencia, presupuesto.

- Profesor-investigador titular del Departamento de Estudios Sociopolíticos y Jurídicos del Instituto Tecnológico y de Estudios Superiores de Occidente (ITESO). dvelasco@iteso.mx rioro de la situación en la que desarrollan su trabajo y que más de veinte informes de organizaciones nacionales e internacionales denuncian que el oficio de luchar por los derechos humanos es un oficio de altísimo riesgo. Hemos analizado diversas situaciones de conflicto que enfrentan y este artículo pretende analizar la principal oposición que se da entre DDH que participan en el amplio y plural movimiento de los DH en México, por un lado, y por el otro, todo el personal que integra el conjunto de organismos autónomos, la Comisión Nacional de los Derechos Humanos (CNDH) y las treinta y dos comisiones estatales (CEDH): el sistema ombudsman.

* Colaboración de: Paola J.Anaya C., L. Celeste Ortiz R.,Andrea L. Ramírez R.y Sarahí Romo U., alumnas de Relaciones Internacionales del ITESO. 
La gravedad de la violencia en nuestro país, favorecida y protegida por agentes del Estado y el bajo perfil desempeñado por los organismos autónomos, nos interrogan por las causas estructurales que favorecen que estos últimos disfruten de enormes presupuestos y que el movimiento de DH haga la tarea con presupuestos precarios, insuficientes o nulos, y poniendo en riesgo la vida de sus integrantes. Este artículo lo hemos concluido al final del proceso por el que el Senado de la República elige al nuevo titular de la $\mathrm{CNDH}$, en medio de los mayores cuestionamientos a su desempeño. La elección recayó en el Lic. Luis Raúl González Pérez, con amplio respaldo de senadores. El desafío de hechos como la ejecución de civiles a manos del ejército en Tlatlaya o la desaparición de cuarenta y tres normalistas de Ayotzinapa, hace relevante un ejercicio como el que presentamos.

La no reelección o ratificación de Raúl Plascencia al frente de la CNDH hace eco a las denuncias de su mal desempeño, de haber favorecido la caída de la credibilidad y confianza en la institución creada para defender al pueblo de México de cualquier abuso de poder. Por otra parte, la elección de un nuevo titular, con fuertes vínculos con el Instituto de Investigaciones Jurídicas de la UNAM, por un lado despierta esperanzas y por el otro genera serias dudas sobre su real autonomía y sobre si su elección no fue, una vez más, un nombramiento político.

En la década de los setenta y principios de los ochenta surgen los primeros colectivos de DH. Su desarrollo e impacto, articulado a la presión internacional, tanto de organizaciones civiles como de organismos del Sistema Interamericano y del sistema ONU, a la par de las negociaciones del Tratado de Libre Comercio de América del Norte (TLCAN), dan lugar al surgimiento del sistema ombudsman en México, que no es sino una muestra de los intentos oficiales del Estado mexicano por implementar el Derecho Internacional de los Derechos Humanos (DIDH). 
Para abordar este análisis del sistema ombudsman en México, nos orientamos por los Principios de París (PP), un conjunto de recomendaciones que la Asamblea General de la ONU adoptó para impulsar la creación de Instituciones Nacionales de Protección de los Derechos Humanos (INDH) (Asamblea General de la ONU, 1993). Estos PP marcaron el inicio de la cooperación y estandarización de las INDH a nivel internacional, representando la principal fuente de estándares internacionales para su creación y detallando sus competencias, responsabilidades, composición, garantías de independencia y métodos de operación. En este sentido, los PP se toman como un referente clave para el análisis del buen funcionamiento del sistema ombudsman.

Por otra parte, el International Council on Human Rights Policy (ICHRP), fundado a finales de los noventa por Mary Robinson (ex Alta Comisionada para los Derechos Humanos de la ONU), reúne a especialistas en DH de diversas partes del mundo, llevando a cabo dos investigaciones sobre el funcionamiento de las INDH (también estableció un conjunto de recomendaciones que refuerzan los indicadores elegidos). La primera investigación se llama Desempeño y Legitimidad: Instituciones Nacionales de Derechos Humanos (ICHRP, 2000); toma como referencia para evaluar su eficacia la evolución de diferentes rubros, como son: sus técnicas de investigación; su legitimidad y su grado de compromiso; su capacidad para ocuparse de casos; su formación e historial; y la forma en que aplican el DIDH. La investigación evalúa principalmente tres indicadores que son la legitimidad, la accesibilidad y los vínculos, concluyendo que son pocas las comisiones en las que sus directivos provengan de ONG o de grupos vulnerables, además de señalar que sus vínculos deben orientarse más hacia las ONG y organizaciones de la sociedad civil ya que son una fuente esencial de información y desempeñan un papel valioso y práctico en la identificación de cuestiones y casos. La segunda investigación se titula Evaluar la Eficacia de 
las Instituciones Nacionales de Derechos Humanos (ICHRP, 2005). Nos centramos en el apartado II, relacionado a los indicadores, en el cual se analiza el grado en que las INDH cumplen de manera efectiva con su mandato de promover y proteger los derechos humanos. Igualmente, su estudio evalúa la manera en que las INDH adquieren legitimidad y buena reputación con base en su efectividad.

En febrero de 2008, Human Rights Watch (HRW, 2008) analiza el desempeño de la CNDH, del que destacamos una de sus conclusiones fundamentales: "[...] cuando se trata de impulsar medidas para mejorar el pobre historial de violaciones de derechos humanos en México, a través de asegurar un recurso efectivo a las víctimas y de promover reformas estructurales, la actuación de la $\mathrm{CNDH}$ ha sido decepcionante"; además, afirma:

la razón del limitado impacto de la CNDH radica en sus propias políticas y prácticas. La CNDH no ha ejercido plenamente su amplio mandato ni maximizado el uso de sus cuantiosos recursos. Una y otra vez, la $\mathrm{CNDH}$ no impulsa a las instituciones del Estado a reparar los abusos que ha documentado, no promueve las reformas necesarias para prevenir abusos futuros, no se opone a leyes, políticas y prácticas abusivas y contrarias a estándares internacionales de derechos humanos, no entrega ni difunde información que posee sobre casos de derechos humanos y no siempre se relaciona constructivamente con actores claves que buscan promover el progreso de los derechos humanos en México (HRW, 2008).

Finalmente, el informe de HRW nos advierte sobre la oposición que analizamos en este trabajo, para denunciar la poca o nula colaboración de la CNDH con otras organizaciones y afirma tajantemente: "La CNDH no ha creado una relación constructiva con distintos actores que pueden contribuir a mejorar la situación de los derechos humanos en México" (HRW, 2008).

El estudio de Elizondo y Magaloni (2010), publicado por el Centro de Investigación y Docencias Económicas, ratifica 
lo dicho por HRW: que el Sistema Ombudsman Mexicano es visto como el más grande -con treinta y dos comisiones estatales, procuradurías estatales de derechos humanos y la CNDH-, y el más caro de América Latina. Lachenal (et al., 2009), construye un modelo ideal a partir de cuatro principios: proactividad, eficiencia, transparencia y pluralidad. La hipótesis que manejan es la prevalencia de un modelo conservador que privilegia el formalismo jurídico por encima de la defensa y protección de los DH en oposición a un modelo progresista que privilegia la participación ciudadana, la colaboración con las ONG especializadas en derechos humanos y la protección y defensa de los derechos humanos por encima de los funcionarios públicos o representantes de los poderes fácticos. Este estudio, como pocos, denuncia la cercanía de la mayoría de los titulares de las CEDH y la CNDH a los titulares de los poderes ejecutivos -estatales y federal-, por lo que, señalan, el nombramiento de un presidente de CEDH o CNDH es un nombramiento político, con todas las consecuencias que implica defender a los gobernantes y no a las víctimas de violaciones a los $\mathrm{DH}$.

Nuestro análisis, con todos estos referentes, lo orientamos a contrastar la oposición entre los DDH y las causas estructurales por las que, en esta oposición, las organizaciones civiles, profesionales y voluntarias, quedan más expuestas a la represión por encarcelamiento -innumerables presos políticos- o por tortura, desaparición forzada o ejecución extrajudicial; ante tales violaciones, no hay indicio alguno de que el sistema ombudsman levante la voz y confronte a los responsables (Lachenal et al., 2009). De esta manera, escogimos cinco indicadores: presupuesto; mecanismo de elección-autonomía; relación entre quejas, recomendaciones recibidas y derechos humanos más violentados; la relación con la problemática del Estado y la relación de las CEDH con las ONG. Comenzamos con el indicador del presupuesto anual disponible. En su "Composición y garantías de inde- 
pendencia y pluralismo", numeral dos, los PP señalan: "La institución nacional dispondrá de créditos suficientes. Esos créditos deberán destinarse principalmente a la dotación de personal y locales propios, a fin de lograr la autonomía respecto del Estado y no estar sujeta a controles financieros que podrían limitar su independencia." (Asamblea General de la ONU, 1993). Para el indicador de la elección, los PP establecen lo siguiente en su numeral tres:

En el interés de la estabilidad del mandato de los miembros de la institución nacional, sin la cual no habrá una verdadera independencia, su nombramiento se hará mediante acto oficial en el que se señale un plazo determinado de duración del mandato. Este podrá prorrogarse bajo reserva de que se siga garantizado el pluralismo de la composición (Asamblea General de la ONU, 1993).

El tercer indicador que utilizamos es la relación entre quejas y recomendaciones, por un lado, y por el otro, el tipo de derecho humano vulnerado. El apartado C de los PP, "Modalidades de Funcionamiento", contempla el "examinar libremente todas las cuestiones comprendidas en el ámbito de su competencia [...] a propuesta de [...] cualquier solicitante" (Asamblea General de la ONU, 1993). El indicador que construimos tiene que ver, por una parte, con la relación que existe entre número de quejas recibidas y el número de recomendaciones emitidas, pero también con establecer la relación con el tipo de derechos vulnerados. La hipótesis que manejamos es que la mayoría de los organismos públicos atienden al tipo de derechos vulnerados que menos los comprometa políticamente y, por el contrario, bajan la presión ante la comisión de delitos de lesa humanidad como la tortura y su modalidad de violación sexual, la desaparición forzada y la ejecución extrajudicial, todos ellos cometidos por agentes gubernamentales.

Todos los referentes mencionados, desde los PP hasta análisis más focalizados en una $\mathrm{CEDH}$, subrayan el divor- 
cio entre el sistema ombudsman -salvo excepciones-y las problemáticas sociales más acuciantes; o como señala el estudio de Lachenal (et al., 2009), una relación inversamente proporcional: entre mayor cercanía al gobernante en turno, menor colaboración con las ONG que sí enfrentan los problemas sociales, luchan por la defensa y protección de los derechos humanos y arriesgan sus vidas.

El indicador central es el de la relación de los organismos públicos con las Organizaciones No Gubernamentales Defensoras de Derechos Humanos (ONGDDH); los referentes utilizados nos permiten denunciar la ausencia de colaboración y recomiendan la posibilidad de que los titulares de las CEDH sean elegidos entre activistas de las ONGDDH. En su apartado $\mathrm{C}$, numeral siete, los PP son explícitos para establecer esta relación, además del reconocimiento de su labor: "establecer relaciones con organizaciones no gubernamentales que se ocupen de la promoción y protección de los derechos humanos [...], habida cuenta de la importancia fundamental de la labor de esas organizaciones para ampliar la acción de las instituciones nacionales" (Asamblea General de la ONU, 1993). HRW (2008) es explícito: "debería promover la participación de la sociedad civil en el procedimiento que utilice para examinar candidatos para la presidencia y el Consejo Consultivo de la CNDH". Al especificar el procedimiento, prácticamente recomienda elegir entre las propuestas de las ONGDDH.

Con este panorama, elegimos ocho CEDH y la CNDH, con los siguientes criterios: el tamaño de su presupuesto anual, la mayor o menor autonomía en la elección de sus titulares, la problemática social que se vive en sus estados y la presencia relevante de ONGDDH. Las CEDH que analizamos son: Chiapas, Chihuahua, Distrito Federal, Guerrero, Jalisco, Michoacán, Oaxaca y Veracruz.

El artículo sintetiza varias hipótesis que lo guían. La mayor es que este sistema ombudsman es el más caro del 
mundo; otra es la ausencia de autonomía real de las CEDH, respecto al Ejecutivo; otra señala el poco impacto que tienen las CEDH respecto a la problemática económica y social de los estados en donde se desempeñan. Finalmente, está la hipótesis de que la oposición o competencia, en todos los sentidos, entre las CEDH y las ONG y sus redes que operan en cada estado, sólo demuestra, una vez más, que las ONG hacen la tarea de las CEDH, casi sin presupuesto y con enorme riesgo de sus vidas.

\section{La burocracia dorada de los derechos humanos}

El presupuesto describe la cantidad económica destinada anualmente a la CEDH para que desempeñe sus labores. Los PP y el ICHRP recomiendan: las INDH deben realizar la gestión económica de sus presupuestos, y estos deben ser acordados por instituciones independientes del Poder Ejecutivo, siendo sometidas con regularidad a un examen financiero. Van los datos:

\begin{tabular}{lrrrrrr} 
Comisión & \multicolumn{6}{c}{ Presupuesto (en millones de pesos) } \\
& \multicolumn{1}{c}{2009} & \multicolumn{1}{c}{2010} & \multicolumn{1}{c}{2011} & \multicolumn{1}{c}{2012} & \multicolumn{1}{c}{2013} & \multicolumn{1}{c}{2014} \\
CNDH & 912.500 & 889.578 & $1,101.717$ & $1,280.276$ & $1,375.127$ & $1,416.381$ \\
DF & 263.00 & 271.00 & 281.00 & 286.00 & 303.00 & 315.00 \\
Jalisco & 69.49 & 91.57 & 91.57 & 117.15 & 122.84 & 137.30 \\
Chiapas* & 27.46 & 28.20 & 29.51 & 73.29 & 70.31 & 65.85 \\
Michoacán & 36.02 & 31.60 & 40.33 & 47.30 & 49.50 & 39.40 \\
Guerrero & 36.10 & 39.61 & 44.03 & 44.74 & 46.98 & 47.50 \\
Chihuahua & 20.14 & 24.00 & 25.76 & 31.71 & 43.46 & $\mathrm{n} / \mathrm{d}$ \\
Veracruz & 36.00 & 38.00 & 34.00 & 41.00 & 42.00 & 46.50 \\
Oaxaca & 24.82 & 26.04 & 26.04 & 26.04 & 26.04 & 27.47 \\
\hline
\end{tabular}

*Para el caso de Chiapas, se solicitó información vía INFOMEX y otros datos se obtuvieron del estudio del 2011 "Comisiones Estatales de Derechos Humanos” del Centro de Estudios Sociales y de Opinión Pública de la Cámara de Diputados. Cabe destacar que la información difiere de una instancia a la otra.

Fuente: elaboración propia con información de los sitios web de las CEDH, artículo de El Informador (14/07/2014) y solicitudes de información vía INFOMEX. 
En general, todas las CEDH manifiestan una tendencia ascendente y llama la atención el presupuesto de la $\mathrm{CNDH}$, el más alto. Según Enrique Méndez en su artículo para $L a$ Jornada del 4 de noviembre de 2013, a nivel nacional el gasto para DH en 2014 fue de $\$ 2788$ millones de pesos, de los cuales $\$ 1426.80$ millones pesos fueron para la CNDH, es decir, el 51.17\%.En opinión de la Red Nacional de Organismos Civiles de Derechos Humanos "Todos los Derechos para todas y todos" (REDTDT): "el alto presupuesto que tiene la CNDH es contrario en relación a su eficacia”. En este sentido, la CNDH con los recursos que dispone, podría hacer mucho más de lo que actualmente realiza (REDTDT, 2013).

Relación entre la población y el presupuesto: gasto per cápita de los organismos de $\mathrm{DH}$

\begin{tabular}{lccc} 
Estado & $\begin{array}{c}\text { Población total } \\
\text { (2010) }\end{array}$ & $\begin{array}{c}\text { Presupuesto comisión } \\
(2010, \text { millones de pesos) }\end{array}$ & $\begin{array}{c}\text { Gasto per cápita } \\
(2010)\end{array}$ \\
DF & $8,851,080$ & 271.00 & $\$ 30.71$ pesos \\
Jalisco & $7,350,682$ & 91.57 & $\$ 12.46$ pesos \\
Guerrero & $3,388,768$ & 39.61 & $\$ 11.68$ pesos \\
CNDH & $112,336,538$ & 889.578 & $\$ 7.91$ pesos \\
Michoacán & $4,351,037$ & 31.60 & $\$ 7.26$ pesos \\
Chihuahua & $3,406,465$ & 24.00 & $\$ 7.04$ pesos \\
Oaxaca & $3,801,962$ & 26.04 & $\$ 6.85$ pesos \\
Chiapas & $4,796,580$ & 28.20 & $\$ 5.8$ pesos \\
Veracruz & $7,643,194$ & 38.00 & $\$ 4.97$ pesos \\
\hline
\end{tabular}

Fuente: elaboración propia con base en datos del INEGI.

El número de habitantes del D. F. es más del doble que el de las otras entidades; sin embargo, llama la atención que su presupuesto no sea proporcional en ese sentido, sino que es aproximadamente nueve veces más alto. El D. F. cuenta con un gasto per cápita significativamente mayor a las otras comisiones. En contraste con la CEDHDF, la de Veracruz, a pesar de ser el estado líder en asesinatos de defensoras y defensores de derechos humanos y de periodistas en par- 
ticular, tiene un gasto per cápita de tan solo $\$ 4.97$ pesos, el más bajo de todos. Por su parte, Chiapas es el segundo estado con menor gasto per cápita; sin embargo, el salario de su titular es de $\$ 116626$ pesos, uno de los más altos de todo el país. Las CEDH dedican más recursos a la nómina que a las actividades de defensa de los DH, como podemos ver en la siguiente tabla:

\section{Gasto total de los organismos de DH destinado a nómina y salarios de los titulares de las comisiones}

\begin{tabular}{|c|c|c|c|c|}
\hline Estado & $\begin{array}{l}\text { Presupuesto total } \\
\text { en millones de } \\
\text { pesos (2014) }\end{array}$ & $\begin{array}{c}\text { Gastos de } \\
\text { "Servicios } \\
\text { Personales"o } \\
\text { Nómina }\end{array}$ & Porcentaje & $\begin{array}{l}\text { Salario del } \\
\text { titular en } \\
\text { miles de pesos } \\
\text { (2014) }\end{array}$ \\
\hline DF & $\$ 315.00$ & $\$ 264.26$ & $83.80 \%$ & $\$ 116,518$ \\
\hline Veracruz & $\$ 46.50$ & $\$ 38.32$ & $82.4 \%$ & $\$ 81,130$ \\
\hline Oaxaca & $\$ 27.47$ & $\$ 22.93$ & $81 \%$ & N/D \\
\hline Chiapas & $\$ 65.85$ & $\$ 49.32$ & $74.89 \%$ & $\$ 116,626$ \\
\hline CNDH & $\$ 1426.80$ & $\$ 1020.00$ & $71.48 \%$ & N/D \\
\hline Michoacán & $\$ 39.00$ & $\$ 18.75$ & $48.07 \%$ & N/D \\
\hline Jalisco & $\$ 137.30$ & N/D & N/D & $\$ 144,853$ \\
\hline Guerrero & $\$ 47.50$ & N/D & $\mathrm{N} / \mathrm{D}$ & N/D \\
\hline Chihuahua & N/D & N/D & $\mathrm{N} / \mathrm{D}$ & N/D \\
\hline
\end{tabular}

Fuente: elaboración propia con datos del INEGI, de las páginas oficiales de las CEDH y artículo de El Informador (14/07/2014).

Como alto contraste, el presupuesto total de la Comisión Interamericana de Derechos Humanos en el 2013, fue de $\$ 291.726$ millones de pesos, ${ }^{1}$ el de la Oficina del Alto Comisionado de las Naciones Unidas para los Derechos Humanos del bienio 2008-2009 fue de $\$ 2515.640$ millones de pesos ${ }^{2}$ y, como dijimos, en México fue de $\$ 2700.880$ millones de pesos. Así comprobamos la hipótesis de que nuestro país tiene el sistema ombudsman más caro del mundo. Lamen-

I. Tipo de cambio a I3.0624 del día 3I de diciembre del 2013.

2. Considerando el tipo de cambio a 10.7 del día 22 de septiembre del 2008. 
tablemente, mayor gasto no representa mejor atención o menores violaciones a $\mathrm{DH}$.

\section{Conclusiones del primer indicador}

Las INDH en México no cumplen en su totalidad con los lineamientos de los PP, ni los sugeridos por el estudio del ICHRP. En primera instancia, los presupuestos son asignados por el Poder Ejecutivo y el Poder Legislativo, contrario a las recomendaciones del ICHRP. Además, los organismos no atraviesan por un examen periódico financiero, existe opacidad en la difusión de información sobre los presupuestos y tampoco son organismos transparentes. Asimismo, las INDH en México cuentan con presupuestos adecuados pero con gastos inadecuados, ya que estos van prioritariamente destinados a los sueldos y no a la mera protección y promoción de los derechos humanos, la cual es su principal función. Finalmente, a pesar de los altos recursos que tienen, son organismos altamente centralizados que no cuentan con suficientes oficinas en zonas rurales, ni personal que pueda atender a poblaciones indígenas en sus lenguas natales, entre otros aspectos. A partir de lo expuesto anteriormente se puede constatar que las comisiones carecen de autonomía e independencia por parte del Poder Ejecutivo en cuanto a los presupuestos, lo cual nos introduce al siguiente indicador a analizar: mecanismos de elección-independencia-autonomía.

\section{Al servicio de los gobiernos locales y del federal}

El análisis del mecanismo de elección y del nivel de autonomía de las CEDH, es pertinente dado que la manera en que se elige al titular contribuye a determinar su nivel de autonomía. Es importante señalar que las leyes orgánicas de dichas CEDH, tienen un avance significativo con respecto al nivel de autonomía de las mismas, resaltando 
su independencia del Estado; sin embargo, en la práctica la oposición que analizamos es justamente entre defensores que participan en el sistema ombudsman resultado de una decisión política, y defensores que participan en las ONG y variedad de colectivos, organizaciones y movimientos sociales que reivindican los DH y que sus prácticas se realizan con mayor o menor distancia de las instancias del Estado, en particular del sistema ombudsman en su conjunto.

Los estudios realizados por el ICHRP, señalan que para funcionar bien, las INDH han de ser realmente independientes del Poder Ejecutivo y de las instituciones del gobierno, incluida la judicatura, pero deben tener acceso a tales instituciones y poder influir sobre ellas, recalcando la importancia de no ser portavoces de sus gobiernos en las reuniones internacionales, distinguiendo su estatus del de los gobiernos y el de las ONG. Con base en un análisis comparativo de esas leyes orgánicas y de sus páginas oficiales, encontramos lo siguiente:

Del total de nueve comisiones, seis (CNDH, D. F., Chiapas, Jalisco, Michoacán y Veracruz) abren convocatoria pública para tener propuestas de aspirantes, mientras que Chihuahua, Guerrero y Oaxaca presentan procesos muy opacos: en el caso de Chihuahua, el mecanismo de elección es directamente realizado por los diputados presentes en la sesión correspondiente del Congreso del Estado, sin realizar anteriormente convocatoria pública, siendo el titular elegido por el voto de las dos terceras partes de los mismos; el titular de la comisión de Guerrero es nombrado por el Ejecutivo del estado, con la aprobación del Congreso, con carácter inamovible hasta su jubilación o fallecimiento; y en Oaxaca, también es el gobernador quien propone a la legislatura local una terna de candidatos y la legislatura vota por el titular. En el proceso de nombramiento del titular de las seis comisiones que sí llevan a cabo un proceso de convocatoria pública, este es elegido por el voto de las dos terceras partes 
de los integrantes del Pleno del Congreso del Estado, o, en sus recesos, por su Comisión Permanente. Cabe destacar que en todas las comisiones aquí analizadas se permite la reelección, señalando que en el caso de la CNDH esta sólo se permite una vez. En cinco de ellas - CNDH, Chihuahua, Jalisco, Oaxaca y Veracruz-, la duración del titular es de cinco años, mientras que en Chiapas, Michoacán y el Distrito Federal, la duración es de cuatro años.

En el caso de la CNDH, el ex titular, Raúl Plascencia Villanueva, ha sido considerado por diversas organizaciones de la sociedad civil, como el grupo activista Relevos, como representante del continuismo de la gestión de José Luis Soberanes. Tras calificar el proceso de sucesión del titular de la CNDH como una "farsa", advirtieron que fue elegido por un voto en bloque por parte del PAN y el PRI, lo cual manifiesta la falta de pluralismo señalada por el ICHRP como requisito para tener un mecanismo de elección digno (Notiese, 2008).

En Jalisco, Felipe de Jesús Álvarez Cibrián, actual presidente de la CEDHJ, fue electo para el periodo 2007-2012; sin embargo, su reelección para un segundo periodo tuvo irregularidades, por lo que varias ONG, la Red Jalisciense de Derechos Humanos, el Centro de Derechos Humanos Coordinadora 28 de Mayo, el Comité de América Latina y El Caribe para la Defensa de los Derechos de las Mujeres (CLADEM) Jalisco, entre otros, interpusieron un juicio de amparo el 7 de febrero de 2012 en contra de la reelección del titular. Sin embargo, la SCJN negó dos amparos el 14 de mayo del 2014 (Unión Jalisco, 2014).

En la CDHDF, el sexto tribunal colegiado en materia administrativa ordenó revisar la legalidad y constitucionalidad del proceso de elección del titular, en el cual se designó a Perla Gómez Gallardo. El recurso de amparo fue presentado el 26 de noviembre de 2014 por el consejero de la CDHDF, Manuel Fuentes Muñiz, y pese a que fue rechazado en primera instancia, dicho tribunal determinó declarar fundada 
la queja Q.A. 202/2013, y ordenó al juez décimo de distrito en materia administrativa del Distrito Federal admitir la demanda debido a la opacidad del proceso, dado que se ocultaron intencionalmente a la opinión pública los criterios de evaluación, el número y la opinión de las organizaciones sociales y las personas participantes, y a la omisión de un dictamen fundado y motivado por la Comisión de Derechos Humanos de la Asamblea Legislativa del Distrito Federal (CDH-ALDF) para garantizar la preservación de la autonomía de la CDHDF.

\section{Conclusiones del segundo indicador}

Observamos cómo de una u otra manera estos nueve organismos se alejan de lo manifestado por los PP y los estudios del ICHRP, distanciándose de la necesidad de verdadera independencia por parte de las CEDH y la CNDH hacia el Poder Ejecutivo y las instituciones del gobierno, y llevando a cabo un proceso de nombramiento opaco, lleno de controversias y polémica.

\section{La relación desigual entre "quejas" y "recomendaciones" y los derechos más vulnerados}

Según Lachenal (et al., 2009), entre las facultades mínimas con las que cuenta el sistema ombudsman para cumplir con su naturaleza jurídica se encuentra el recibir quejas sobre presuntas violaciones a derechos humanos, así como el formular recomendaciones públicas, no vinculantes, denuncias y quejas ante las autoridades respectivas. A partir de ello, el tercer indicador que utilizamos en este artículo, tiene que ver, por una parte, con la relación que existe entre el número de quejas recibidas y el número de recomendaciones emitidas y su relación con el tipo de derechos vulnerados. En el caso de Chiapas, según información obtenida mediante la solicitud de información vía INFOMEXCEDH/DGQOG/489/2014, 
desde el 01 de enero del 2009 hasta el 31 de diciembre del 2013 recibieron 15573 quejas. Este elevado número no representa realmente una mejora en la atención de casos, ni en la situación de los derechos humanos de los ciudadanos. Asimismo, según la respuesta obtenida, los derechos más vulnerados -anunciados de manera descendente- son: el derecho a la educación, el derecho a la integridad personal y el derecho a la legalidad. En los últimos cinco años, han sido emitidas cuarenta recomendaciones, según información recabada en respuesta a la solicitud de folio 9702. Las autoridades más señaladas de forma descendente son: los Ayuntamientos Municipales, el Instituto de Seguridad Social para los Trabajadores del Estado (ISSSTE) en Chiapas, la Procuraduría General de Justicia, y la Secretaría de Educación. Es importante señalar que el número de recomendaciones es muy bajo en relación al número de quejas que reciben en comparación con otras Comisiones, que en promedio realizan más de cuarenta recomendaciones por año, como Guerrero.

En Chihuahua, de acuerdo al Informe Anual 2013 de la Comisión Estatal de Derechos Humanos de Chihuahua (CEDHCHU, 2013) se recibieron un total de 1344 quejas. Las quejas que emitían las víctimas eran por la violación de sus derechos como: el derecho a la libertad, el derecho a la legalidad y a la seguridad jurídica, y el derecho a la procuración de justicia. Ante esta situación, se emitieron veintiocho recomendaciones dirigidas a funcionarios públicos de diversas dependencias de nivel municipal y estatal, agentes de las corporaciones policiacas preventivas y de la Fiscalía General del Estado.

En el Distrito Federal, el número de quejas recibidas en el 2013 fue de 8 652; resalta como principal derecho violado la violación a la integridad personal seguido de la violación a la garantía de seguridad jurídica, la violación a la libertad y posteriormente se encuentran la violación al derecho a la 
salud y la garantía del debido proceso. Entre las principales recomendaciones se encuentran: la reparación a daños a las víctimas o sus familiares; el acto de reconocimiento de responsabilidad a favor de los afectados, y que se elabore y ejecute un programa de difusión y capacitación para que los elementos de policía conozcan y apliquen el Manual de Técnicas para el Uso de la Fuerza de la Secretaría de Seguridad Pública del Distrito Federal. Durante el mismo periodo, se han emitido cuarenta recomendaciones hacia la Procuraduría General de Justicia del Distrito Federal, veinte recomendaciones hacia la Secretaría de Seguridad Pública del Distrito Federal y catorce recomendaciones para la Secretaría de Salud del Distrito Federal.

Guerrero no presenta número de quejas en la página web oficial de la Comisión y no se obtuvo respuesta a la solicitud de información. Sin embargo, con base en la investigación documental en la página de internet de la Comisión de Defensa de los Derechos Humanos del Estado de Guerrero, con respecto a las recomendaciones, en el 2010 se emitieron ciento cincuenta y tres, en el 2011 fueron ciento treinta y ocho, en el 2012 emitieron ciento dieciséis, en el 2013 solo sesenta y siete y hasta septiembre de 2014, se realizaron veintisiete. Tales recomendaciones se hicieron por la vulneración de los derechos a la seguridad jurídica y a la seguridad personal. Las autoridades más señaladas por las recomendaciones del Consejo de Defensa de los Derechos Humanos de Guerrero fueron: servidores públicos municipales, servidores públicos de la Procuraduría General de Justicia del Estado, Ejército Mexicano y la Secretaría de Educación (CDDHEG, s/f).

En Jalisco, las quejas por supuestas violaciones a los DH incrementaron 8.7 veces más en 2013 con respecto al 2012. Cifras de la Comisión precisan que durante 2012 se presentaron doscientas veintidós quejas, mientras que al finalizar 2013 la cifra llegó a 1951 quejas. Dichas quejas 
fueron realizadas principalmente por la violación de los derechos ambientales, derechos de la niñez, derechos de la vejez, derecho a la integridad y derecho a la seguridad personal. En 2013 se emitieron un total de cuarenta y seis recomendaciones, dirigidas principalmente al secretario de educación Jalisco, al secretario de salud y al fiscal regional del estado.

En Michoacán, durante el 2013 se recibieron un total de 2703 quejas. Sin embargo, los municipios de Morelia, Zitácuaro y Lázaro Cárdenas se presentan como los municipios que más quejas han recibido durante estos dos años, lo cual se relaciona con la problemática del estado. Los principales hechos violatorios con el mayor número de quejas en orden descendente son la detención ilegal, el abuso de autoridad y la negativa a la educación y a la atención médica. En el caso de las recomendaciones, hasta octubre del 2013 se emitieron cincuenta y tres; esto nos dice que se manifiesta una falta de información relacionada al número exacto de recomendaciones emitidas, basadas en quejas que van ligadas directamente con los principales hechos violatorios mencionados anteriormente, donde las principales autoridades a las que van dirigidas son la Procuraduría General de Justicia del Estado, la Secretaría de Educación Pública del Estado y los Ayuntamientos mencionados.

La Defensoría de los Derechos Humanos del Pueblo de Oaxaca (DDHPO), recibió durante el 2013 un total de 3140 quejas, por vulneración a los derechos de legalidad y seguridad jurídica, ocupando el primer lugar en quejas recibidas, seguido de la violación al derecho a la libertad y la detención arbitraria. Sólo hasta el mes de febrero de 2014 se habían recibido cuatrocientas treinta y un quejas. Respecto a las recomendaciones, sólo hay información del 2010, y en este año se emitieron sesenta y un recomendaciones; las principales autoridades a las que se dirigen, y también señaladas como las responsables de las violaciones a los derechos 
humanos, son: autoridades municipales, seguidas de la Procuraduría General de Justicia del Estado, la Secretaría de Seguridad Pública del Estado y el Instituto Estatal de Educación Pública de Oaxaca (DDHPO, 2014).

En el caso de Veracruz, en la página web oficial de la Comisión no hay información alguna relacionada al número de quejas recibidas; sólo hay información sobre los derechos vulnerados: el derecho a la libertad, integridad física, y derecho a la seguridad jurídica; un total de sesenta y un recomendaciones hacia los presidentes municipales, la Secretaría de Seguridad Pública y la Procuraduría General de Justicia. De enero a septiembre de 2014, se habían violentado los derechos a la seguridad jurídica, integridad física y a la libertad personal, y se habían emitido veintitrés recomendaciones para la Secretaría de Seguridad Pública, presidentes municipales y Ayuntamientos y la Procuraduría General de Justicia.

En el caso de la CNDH, según Informe 2013, se recibieron 45972 quejas, de las cuales 6063 eran por la vulneración del derecho a la salud y 3454 por negligencias médicas; dos de cada diez principales hechos violatorios, están vinculados con el derecho a la protección de la salud. Ante este hecho, durante el mismo año se emitieron ochenta y seis recomendaciones dirigidas a diversas autoridades e instituciones, pero las principales que encabezan este indicador son la SEDENA y el IMSS.

\section{Conclusiones del tercer indicador}

Constatamos que en todas las comisiones analizadas las quejas más frecuentes son, en orden descendente: la vulneración del derecho a la legalidad y seguridad jurídica, libertad, seguridad personal, integridad física y personal, así como el acceso a la salud. Encontramos una variedad enorme en el número de recomendaciones emitidas, pues cada CEDH sigue criterios diferentes por el tipo de queja, 
autoridad señalada o problemática que más prevalezca en cada uno de los estados o a nivel nacional. En orden descendente, las autoridades más señaladas son: la Secretaría de Seguridad y Protección Ciudadana, funcionarios de nivel municipal y estatal y la Procuraduría General de Justicia del Estado. Destaca la opacidad en las CEDH y la variedad con la que manejan quejas, recomendaciones, derechos vulnerados y autoridades a las que dirigen sus recomendaciones.

Entre la enfermedad y sus tratamientos paliativos -El arte de mirar para otro lado

¿Cómo se relaciona este irregular desempeño del sistema ombudsman con las problemáticas sociales y políticas que existen en las entidades que analizamos? La hipótesis del indicador anterior es que las comisiones miran para otro lado al momento de emitir recomendaciones. En este apartado buscamos dar cuenta de las problemáticas más graves, las cuales deberían realmente atenderse, a nivel nacional y estatal. En México existen tres problemáticas comunes en los estados analizados, que no son tomadas en cuenta por las comisiones al momento de emitir recomendaciones, estas son: la pobreza, la impunidad y la inseguridad.

En México, según datos del Informe sobre la Pobreza en México 2012 del Consejo Nacional de Evaluación de la Política de Desarrollo Social (CONEVAL), había "53.3 millones de personas en condición de pobreza, de las cuales 41.8 millones vivían en pobreza moderada y 11.5 millones en pobreza extrema”. Algunas de las comisiones estatales que analizamos en este artículo -Chiapas, Guerrero, Oaxaca, Michoacán y Veracruz- enfrentan a más de la mitad de la población viviendo en situación de pobreza. Los estados sureños son los que sufren mayor desigualdad; sin embargo, Chiapas es el que concentra mayor nivel de pobreza; según 
el CONEVAL (2012) "tres de cada cuatro habitantes eran pobres y uno de cada tres era pobre extremo en el 2012". Otro problema importante en Chiapas es la migración en todas sus modalidades. Según datos del Instituto Nacional de Estadística y Geografía (INEGI) el 1.2\% de la población total de Chiapas en 2010 se compone de inmigrantes recientes y $2.5 \%$ de la población total ha migrado a otros estados del país y a los EE.UU., motivados por la pobreza y el ambiente de violencia en el que viven.

En Guerrero, según el CONEVAL, el 69.7\% de la población es pobre, el $78.5 \%$ no tiene acceso a la seguridad social, el $26.8 \%$ tiene rezago educativo y el $31.7 \%$ de la población sufre de pobreza extrema. Pero además de la pobreza, entre las problemáticas más graves del estado están los asesinatos y amenazas a DDH, y los mega-proyectos que despojan de sus tierras a campesinos a favor de empresas transnacionales. El gobierno realiza la desarticulación de organizaciones sociales mediante el asesinato de sus líderes, el acoso constante y las amenazas a sus integrantes.

Veracruz encabeza la lista de estados con mayores carencias por acceso a los servicios de salud con el $25.7 \%$ de su población, y por carencia a la alimentación con el 31.2\%. Sin embargo, la problemática más alarmante es el asesinato de periodistas. Según Artículo 19, en una nota para MVS Noticias del 22 de julio de 2014, "Veracruz es el lugar más peligroso del mundo para los comunicadores y periodistas [...] De acuerdo a esta organización, del año 2000 al 2013 han sido asesinadas/os 76 periodistas, y 16 más están desaparecidas/os desde el 2003”. A pesar de estas cifras, entre las recomendaciones que hace la CEDH de Veracruz no se encuentran aquellas dirigidas a atacar este problema.

En Oaxaca, con el 61.9\% de la población en pobreza, destacan dos problemáticas principales: la primera, los altos niveles de marginación a pueblos indígenas, incluyendo la violación de derechos humanos por falta de atención médica, 
como el caso de Irma, la indígena mazateca que dio a luz en el patio de un centro de salud rural en el 2013; la segunda, los mega-proyectos que se desarrollan en México a partir de la violación de los derechos de los pueblos indígenas. Una muestra de ellos es lo que sucede en San Dionisio del Mar, Oaxaca, donde la empresa Mareña Renovables prevé establecer un parque eólico, sin consultar a la población.

En Michoacán destacan dos problemáticas principales: la guerra interna, incluyendo la detención de miembros de autodefensas que luchan contra el crimen organizado y el narcotráfico; y las protestas de profesores agrupados en la Coordinadora Nacional de Trabajadores de la Educación (CNTE) que se oponen a la reforma educativa promovida por el Gobierno Federal. Según declaraciones realizadas por autodefensas, entre ellos el doctor José Manuel Mireles (ahora encarcelado), el 90\% de la policía y autoridades en Michoacán se encuentran coludidas con los Caballeros Templarios. El gobierno criminaliza las acciones realizadas por las autodefensas, tratando así de justificar las violaciones a DH realizadas en su contra, convirtiéndose en la problemática central no sólo de Michoacán, sino de todo el país.

Según un artículo de Ernesto Martínez para La Jornada, integrantes de la CNTE han manifestado desde el año 2013 su inconformidad frente a algunas de las disposiciones de la Reforma Educativa y la Ley de Coordinación Fiscal, iniciando un paro de labores en junio 2014, donde el dirigente magisterial Juan José Ortega Madrigal afirmó que se paralizó el 80\% de los más de 11000 planteles educativos del estado, exigiendo que el gobierno del estado cumpla con mejoras salariales y prestaciones, infraestructura educativa y otorgamiento de plazas. En relación a la pobreza, según el CONEVAL, en 2012 el porcentaje de población en situación de pobreza fue de 54.4\%; mientras que la población en pobreza extrema, aumentó, pasando de $13.5 \%$-597 959 personas-en 2010 a 14.4\% -650 348 personas- en 2012. De acuerdo con 
una nota de CNN México del 03 de junio de 2014, la asociación civil "México Evalúa" afirma que el número de casos de los principales delitos violentos ha sido mayor entre enero y abril de este año en comparación con el mismo periodo de 2013. Respecto a la lucha contra la impunidad, en opinión de Jaime Sánchez "es necesaria la desarticulación de Los Templarios e identificación y detención de los cómplices de los criminales" (2014).

En el D. F. una de las problemáticas principales es la violación de los derechos humanos al agua. La alta densidad de población -y los hábitos de consumo- han generado una fuerte demanda de agua en las últimas décadas.

De acuerdo con el Diagnóstico de Derechos Humanos del D. F. del 2008, "La alta densidad de población -y los hábitos de consumo- han generado una fuerte demanda de agua en las últimas décadas. Según datos oficiales de 2004, se suministra un caudal promedio diario de $32.7 \mathrm{~m}^{3} / \mathrm{s}$ de agua en el Distrito Federal: el uso doméstico representa $44 \%$, mientras que el industrial y comercial, así como el de servicios representan 21\%; sin embargo, por concepto de pérdidas se estima $35 \%$ (debido principalmente a la antigüedad de las tuberías en algunas zonas y al hundimiento regional característico de la zona plana de la ciudad que daña las tuberías). ${ }^{3}$ En el Programa General de Desarrollo del Distrito Federal 2007-2012 se reconoce que el equivalente a una tercera parte del volumen que se inyecta a la red se pierde en fugas (Comité, 2008).

En Jalisco, una de las problemáticas principales es el deterioro ambiental. El desarrollo anárquico y la movilidad urbana, sometidos al lucro comercial y la ganancia desmedida, han deteriorado gravemente nuestros recursos naturales: el 80\% de los ríos están contaminados. Uno de los ríos

3. Cifras para 2004 tomadas de Sistema de Aguas de la Ciudad de México (SACM), Programa de Gestión Integral de los Recursos Hídricos 2004-2009, publicado en la Gaceta Oficial del Distrito Federal el 27 de mayo de 2005, pp. I3-I4. 
más contaminado del país es el Río Santiago. Un lamentable ejemplo de las consecuencias de la contaminación del río es el caso del niño Miguel Ángel López Rocha, quien falleció al caer al río y tragar agua. Otra problemática es la migración en tránsito en la Zona Metropolitana de Guadalajara, que forma parte de la ruta migrante del Pacífico. Según la organización civil FM4 Paso Libre, las personas en migración en tránsito sufren violaciones de DH sistemáticas. Ante esta problemática la CEDHJ, en una nota para Milenio Noticias del 10 de agosto de 2014, afirma que no ha recibido quejas, por lo tanto no ha emitido recomendaciones al respecto.

En Chihuahua, desde la década de 1990, los feminicidios son la problemática principal del estado, con la tasa de feminicidios más alta del mundo en 2010: 34.73 asesinatos por cada cien mil mujeres. Por otro lado, la organización civil Justicia Para Nuestras Hijas, aseguró que detrás de los asesinatos y desapariciones de mujeres en Ciudad Juárez, hay una red de trata de mujeres y denunciaron que a pesar de ello la Fiscalía Estatal no ha seguido esta línea de investigación. A pesar de los miles de asesinatos de mujeres en Chihuahua, y aun con la sentencia de la Corte Interamericana de Derechos Humanos sobre el caso Campo Algodonero en Ciudad Juárez, el feminicidio aún no ha sido tipificado en el Código Penal de Chihuahua. La segunda problemática más fuerte de Chihuahua, que se comparte con el resto del país, es la inseguridad, en particular en la modalidad de secuestro. Según datos del Observatorio Ciudadano de Prevención, Seguridad y Justicia, los secuestros presentaron un incremento del $41 \%$.

\section{Conclusiones del cuarto indicador}

Las problemáticas sociales más graves que se presentan en cada entidad y a nivel nacional, en la mayoría de los casos, no son tomadas en cuenta por las CEDH. Resulta alarmante esta situación, ya que muestra una falla estructural 
y una complicidad con el Estado para maquillar la situación social y política de cada entidad. Debido a esta situación, las organizaciones civiles cuestionan a las CEDH, y entran en conflicto, al grado de presentar denuncias penales contra algunas de ellas.

\section{Entre los que hacen el trabajo y arriesgan la vida y los que disfrutan de altos sueldos}

Según los estudios citados del ICHRP, son pocas las CEDH en las que un porcentaje significativo del personal procede de $\mathrm{ONG}$, lo que muestra cierta renuencia por parte de ambas partes a trabajar en conjunto. Dichos estudios expresan que las INDH más efectivas son aquellas que mantienen una estrecha colaboración con las organizaciones de la sociedad civil, a través del desarrollo de mecanismos que protejan de manera directa los derechos humanos. Pero hay barreras infranqueables, como las que establece la CNDH en sus normas y lineamientos, pues solamente

el personal autorizado por la institución, con fundamento en la normatividad aplicable y en los acuerdos respectivos que suscriba el Presidente, deberá colaborar con organismos no gubernamentales, nacionales e internacionales, para cumplir responsablemente con su misión social de formación, difusión, orientación y defensa de los derechos humanos (CNDH, s/f).

En agosto 2014, durante el coloquio "Evaluación de la Comisión Nacional de los Derechos Humanos" organizado por los partidos del Trabajo y Movimiento Ciudadano en la Cámara de Diputados, representantes de diversas ONG criticaron el papel de la CNDH, al considerar su desempeño como ineficiente, teniendo como prioridad el atender su agenda política en lugar de la defensa de los derechos humanos. El punto de máxima oposición entre ONG y la CNDH se refleja 
en el juicio de amparo contra la CNDH por violaciones a los derechos humanos en el caso de la masacre de setenta y dos personas migrantes en San Fernando, promovido por las víctimas en conjunto con la Fundación para la Justicia y el Estado Democrático de Derecho y Casa del Migrante de Saltillo; el 6 de junio de 2014, el Noveno Tribunal Colegiado en Materia Administrativa del Primer Circuito confirmó la admisión del amparo y rechazó los argumentos de la CNDH quien alegaba que la demanda interpuesta por las víctimas no debió ser admitida por el juzgado de distrito ya que era "notoriamente improcedente admitirla".

En Jalisco, el Centro para la Paz y el Desarrollo (CEPAD $)^{4}$ hizo una encuesta a diversas ONG sobre su relación y participación con la CEDHJ, en donde más de un 20\% de las ONG no tiene convenio y el $7 \%$ no sabe. Ante este panorama, se constata que la CEDHJ resuelve problemáticas principalmente a través de la canalización a otras instituciones y de la conciliación, en lugar de actuar por su cuenta. Como mencionamos anteriormente, destaca la oposición entre ONG y la CEDHJ con respecto a los tres recursos de amparo emitidos por parte de ONG; dos de ellos fueron rechazados por la SCJN, mientras que el primer recurso se encuentra pendiente de resolución.

En el caso de Chihuahua, hasta la fecha no se han firmado convenios con los entes $\mathrm{u}$ organismos antes mencionados, lo que refleja la nula colaboración entre las ONG y la CEDH Chihuahua.

En Michoacán no hay ONG que formen parte de la REDTDT; sin embargo, dentro de la página oficial de la CEDH de Michoacán, se distinguen dieciséis ONG con las que se ha trabajado en conjunto. La oposición entre ambas instancias se expresa en la oposición entre el Comité de Familiares

4. CEPAD, Análisis y Gestión de la Comisión Estatal de Derechos Humanos de Jalisco. Guadalajara. Información obtenida del Lic. Cesar Octavio Pérez Verónica, miembro del CEPAD, en entrevista personal con él. 
de Personas Detenidas y Desaparecidas Alzando Voces y la CEDH de Michoacán: según una nota de La Jornada del 23 de mayo de 2014, los primeros señalan que la cifra de dieciséis personas desaparecidas que registra la CEDH para mayo de 2014 no corresponde con la realidad, pues destaca la falta de veracidad en sus datos, debido a que, en lo que va del año, la ONG ha contabilizado cincuenta sucesos de un total de ciento noventa y siete casos que tienen registrados.

El D. F. se distingue de las otras entidades porque es menos evidente la oposición entre ONG y la CDHDF, y sí tienen mayor colaboración. Además, es donde hay más organizaciones que forman parte de la REDTDT, con un total de diecisiete. La CDHDF cuenta con un directorio de ciento ochenta y tres organizaciones de la sociedad civil, el cual se puede clasificar en aquellas organizaciones que trabajan por grupo de población, las que trabajan un derecho en particular y las de DH en general. Asimismo, según su página web, a finales de 2013, la CDHDF consolidó el trabajo de vinculación con organizaciones de la sociedad civil a través de la creación de quince agendas ciudadanas. El caso en donde se ve reflejada la oposición entre ONG y la CDHDF es en el del amparo interpuesto por Manuel Fuentes Muñiz contra actos de la ALDF derivados de la elección de Perla Gómez Gallardo como titular de la CDHDF.

En el estado de Oaxaca existen cinco ONG que forman parte de la REDTDT. Es posible identificar algunos casos en donde la DDHPO ha trabajado en conjunto con ONG con respecto a la protección y defensa de los derechos humanos; por ejemplo, la colaboración con cincuenta ONG exigiendo al gobernador Gabino Cué Monteagudo la renuncia del titular de la Secretaría de Salud. No obstante, en agosto de 2014, el Comité de Defensa Integral de Derechos Humanos Gobixha (CODIGODH) advirtió serias deficiencias en la DDHPO, declarando que la misma no se opone a leyes, políticas y prácticas contrarias a estándares internacionales 
de derechos humanos, ni promueve las reformas necesarias para prevenir abusos futuros, considerando que

Le corresponde a la DDHPO ser proactiva y persistente para mejorar la situación de los derechos humanos en el estado, y si determina o se percata que leyes, reglamentos, políticas o prácticas contradicen los estándares internacionales de derechos humanos, debería promover su reforma o modificación en pro de los mismos, y en cumplimiento de la Reforma Constitucional de DH (CODIGODH, 20I4).

En el caso de Guerrero, son tres las ONG que forman parte de la REDTDT, además de las Policías Comunitarias y otras organizaciones pequeñas constituidas por familiares de las víctimas. Según el informe del 2013 "Digna Rebeldía”, del Tlalchinollan Centro de Derechos Humanos de la Montaña, en esta entidad "la ausencia de servicios de asesoría jurídica y las prácticas discriminatorias que permean, exigen que el trabajo de DH, amplíe las concepciones tradicionales de la labor de los organismos civiles"; al no tener un buen sistema de justicia en Guerrero, las ONG se ven obligadas a realizar el trabajo de acompañamiento jurídico que le tocaría hacer a otras instituciones, como al Consejo de Defensa de los Derechos Humanos de Guerrero (CODDEHUM).

Chiapas es uno de los estados que tiene más redes de ONG y organizaciones civiles y campesinas trabajando por los derechos humanos. Son ocho las organizaciones que forman parte de la REDTDT. Además, se encuentra el Ejército Zapatista de Liberación Nacional (EZLN), movimiento autónomo que cuenta con un gran apoyo de redes de organizaciones a nivel internacional, nacional y local. La relación con la CEDH Chiapas es de antagonismo y oposición; incluso cuando activistas de una ONG llegaron a ocupar puestos importantes en la CEDH, fueron señalados como traidores por muchos otros activistas en todo el estado. 
En Veracruz, las ONG que forman parte de la REDTDT son tres; lo curioso es que hay cientos de organizaciones de familiares de víctimas de personas desaparecidas, y un movimiento creciente para hacer justicia por los asesinatos de periodistas. La relación que tienen las ONG con la CEDH de Veracruz es de oposición y al mismo tiempo de monitoreo de la situación de los DH en la entidad.

Por último, varias ONG presentaron el pasado 24 de septiembre 2014 ante la Cámara de Diputados una demanda de juicio político contra el exombudsman de la CNDH, Raúl Plascencia Villanueva, señalando que ha faltado a su mandato de defender a las víctimas de violaciones de derechos humanos.

\section{Conclusiones del quinto indicador}

Con excepción de la CDHDF, en general se vive una oposición entre ONG y CEDH, en la que las primeras son quienes realizan el trabajo de las segundas, y quienes exigen mejorías en el funcionamiento de las comisiones, que cuentan con los recursos y la necesaria capacitación de sus funcionarios que los oriente más a las problemáticas de los estados en lugar de enfocarse en su carrera política. Por ello, las comisiones estatales deben implementar medidas que mejoren su funcionamiento y expresen realmente su independencia del Poder Ejecutivo, para que así las ONG dejen de verse como rivales y en cambio se vean como aliadas con las que se puedan trabajar agendas en conjunto, siempre teniendo claro el objetivo común de la protección y defensa de derechos humanos, erradicando las causas que originan las violaciones a los derechos humanos mediante la promoción, difusión, defensa y construcción de una cultura de respeto a los mismos, aun cuando eso suponga enfrentar el poder del Estado.

Aquí es necesario llamar la atención del mensaje que dirigió el nuevo titular de la $\mathrm{CNDH}$, Luis Raúl González 
Pérez, porque justamente propone una estrecha colaboración con organizaciones de la sociedad civil. Es verdad que en todo discurso iniciático aparecen todas las buenas intenciones, pero resulta relevante en el actual contexto de crisis humanitaria y de derechos humanos que padecemos en México. Por ejemplo, señaló como objetivo fundamental de esta nueva etapa "la atención a las víctimas de violaciones a derechos humanos y el abatimiento de la impunidad lacerante" (González, 2014). A renglón seguido afirmó: "Para ello buscaré el diálogo y trabajo conjunto con las personas que demandan nuestra intervención y las organizaciones de la sociedad civil, para que este Organismo Nacional cumpla con las exigencias y aspiraciones legítimas de la sociedad mexicana" (González, 2014).

El nuevo ombudsman nacional es consciente de que para lograr sus propósitos "no basta la sola labor de este organismo nacional. Se requiere del acompañamiento y acción de la sociedad civil, desde sus distintas trincheras" (González, 2014). Un aspecto no menor, es la referencia que hace el nuevo titular de la CNDH a la reforma de la institución:

La CNDH debe transformarse de acuerdo con los dictados de la sociedad. Debemos construir un nuevo paradigma institucional, para actuar con mayor decisión y firmeza, con mayor dinamismo y entrega, sin pausa y con la convicción de ser la voz de aquellos que no la tienen, que la han perdido o que se las han arrebatado. La CNDH tiene poder [...] sabrá hacer uso de él, con total y absoluta responsabilidad, para denunciar con toda su energía las trasgresiones a los derechos humanos (González, 20I4).

Y por si fuera poco, señaló:

Hago expreso mi compromiso de encabezar una CNDH cercana a la sociedad; exigente y demandante ante la autoridad; implacable ante aquellos que desde el poder afrentan $y$ atentan contra la dignidad de 
las personas; incómoda para aquellas autoridades que se olvidan de sus mandantes, y que han hecho del ejercicio público una actividad comodina y ventajosa para sus intereses (González, 20I4).

Las palabras se las lleva el viento, dice el refrán popular, sabiduría ancestral. Queda el desafío a las ONGDDH si le toman la palabra y, más todavía, establecen compromisos de colaboración efectivos, los cuales, tanto para los casos Tlatlaya y Ayotzinapa como para otros miles que quedan ocultos en las ejecuciones extrajudiciales, desapariciones forzadas, casos de tortura y feminicidios en todo el país, son el mayor reto para la plena vigencia de los derechos humanos en México. Si las ONGDDH que participaron en la impugnación de la reelección del anterior titular de la $\mathrm{CNDH}$, hacen lo mismo en cada uno de los estados, no estamos lejos de un real fortalecimiento del sistema ombudsman más caro del mundo con capacidad de enfrentar todos los abusos de poder.

\section{Conclusiones generales}

Podemos constatar que el sistema ombudsman en México es el más caro del mundo, y con un potencial desaprovechado por atender más a la carrera política y evitar confrontar al Estado. Cada uno de los indicadores, muy sintéticamente expuestos, da pie para cuestionarnos sobre la mejor estrategia que impulse al sistema ombudsman a enfrentar el poder del Estado y hacer efectiva la defensa y protección de los derechos humanos; al mismo tiempo que otros DDH enfrentan ese poder y develan las causas estructurales de la ineficiencia y el papel político que juega dicho sistema: ocultar y proteger a los agentes del Estado, quienes de manera sistemática y estructural violan derechos humanos, al grado de cometer delitos de lesa humanidad, al mismo tiempo que denuncian en los foros internacionales la doble cara del Estado mexi- 
cano: hacia fuera, defensor de los derechos humanos; hacia dentro, sistemático perpetrador.

Fecha de recepción: 3 de noviembre de 2014 Fecha de aceptación: 20 de noviembre de 2014

Asamblea General de la ONU (1993). Principios relativos al Bibliografía Estatuto de las Instituciones Nacionales de Promoción y Protección de los Derechos Humanos. Identificación Oficial: Resolución A/RES/ 48/I34. Nueva York. Recuperado de: http://www.un.org/documents/ga/res/48/a48rl34. htm

Asamblea Legislativa de la Cámara de Diputados (2008). Diagnóstico de Derechos Humanos del Distrito Federal. Ciudad de México. Recuperado de:http://www.pdh.df.gob. mx/index.php/informacion-general-del-curso

Bastida, L. (05 de noviembre 2009). "Raúl Plascencia Villanueva, nuevo titular de la CNDH". Notiese. Recuperado de: http://www.notiese.org/notiese.php?ctn_id=3352

Centro de Estudios Sociales y de Opinión Pública de la Cámara de Diputados (20II). Comisiones Estatales de Derechos Humanos. México: Cámara de Diputados. Recuperado de: http://www.google.com.mx/url?sa=t\&rct=j\& $q=\&$ esrc $=s \& f r m=\mid$ \&source $=$ web\&cd $=\mid$ \&ved $=0 C B w Q F$ jAA\&url=http\%3A\%2F\%2Fwww3.diputados.gob.mx\%2 Fcamara\%2Fcontent\%2Fdownload\%2F267278\%2F8I4 207\%2Ffile\%2FContexto_No.I5_derechos_humanos. pdf\&ei=88LbVly3j4j_yQTNuYC4CA\&usg=AFQjCNF uyOI7yQDSzpArDgB4LGj69UZ9jg

CNN México (03 de junio de 20I4). "7 claves para entender y enfrentar la inseguridad en Michoacán”. Recuperado de: http://mexico.cnn.com/nacional/20 /4/06/03/7claves-para-entender-y-enfrentar-la-inseguridad-enmichoacan 
Bibliografía

Comité de Defensa Integral de Derechos Humanos Gobixha A.C. (CODIGO DH) (II de agosto de 20l4). Vacíos y pendientes en la defensa de los \#DDHH en Oaxaca. Oaxaca, Oax. Recuperado de: http://www.codigodh. org/20 I4/08/ I I/vacios-y-pendientes-en-la-defensa-delos-ddhh-en-oaxaca/

Comisión Estatal de los Derechos Humanos de Chihuahua. Artículo 20 de la Ley de Transparencia. Recuperado de: http://www.cedhchihuahua.org.mx/inicio/index.php/ transparencia

Informe 20/3. Recuperado de: http://www.cedhchihuahua.org.mx/portal/Informes/Informe_2013.pdf

Comisión de Defensa de los Derechos Humanos del Estado de Guerrero. Recomendaciones. Sin fecha. Recuperado de: http://www.coddehumgro.org.mx/sitio/

Comisión Nacional de los Derechos Humanos. Normas y Lineamientos. Recuperado de:http://www.cndh.org.mx/ Normas_Lineamientos

- Preguntas frecuentes. Recuperado de: http://www. cndh.org.mx/node/ $90085^{5}$

Comité Coordinador para la elaboración del Diagnóstico y Programa de Derechos Humanos del Distrito Federal (2008). "Diagnóstico de Derechos Humanos del Distrito Federal". Parte III. Núcleo Seguridad Humana, Capítulo II. Derecho al Agua, párrafo 558, pp. I 5 I - I 52. Recuperado de: http://www.pdh.df.gob.mx/index.php/ diagnostico-en-derechos-humanos

Consejo Nacional de Evaluación de la Política de DesarroIlo Social (2012). Informe de Pobreza en México 2012. Recuperado de: http://www.coneval.gob.mx/Informes/Pobreza/Informe\%20de\%20Pobreza\%20en\%20 Mexico\%202012/Informe\%20de\%20pobreza\%20en\%20 M\%C3\%A9xico\%2020I2_I31025.pdf

5. La pregunta: "De las relaciones del personal autorizado por la $\mathrm{CNDH}$ con las ONG". 
Defensoría de los Derechos Humanos del pueblo de Oaxaca. Defensa y protección de los derechos humanos. Recuperado de: http://www.derechoshumanosoaxaca.org/index.php (20I4). Informes estadísticos. Recuperado de: http:// www.derechoshumanosoaxaca.org/informesestadisticos.php

Diario Despertar de Oaxaca (I5 de agosto de 20I4). “ONG denuncia la ineficiencia de la defensoría de derechos humanos". Despertar de Oaxaca. Recuperado de: http://www.despertardeoaxaca.com/?p=24228

El Informador (I4 de julio de 20I4). “La CEDHJ no incide en políticas de gobierno”. Recuperado de: http://www. informador.com.mx/jalisco/20 I 4/538 | 33/6/la-cedhj-noincide-en-politicas-de-gobierno.htm

Elizondo, C.y Magaloni, A. (2010). Nuestros caros defensores de los derechos humanos: el caso de la Comisión Nacional de Derechos Humanos. México: CIDE.

FM4 Paso Libre (20I3). Migración en tránsito por la Zona Metropolitana de Guadalajara: actores, retos y perspectivas desde la experiencia de FM4 Paso Libre. Guadalajara: Prometeo Editores. Recuperado de:http://www.uca.edu.sv/ sociologia/media/archivo/52bdf0_infomefm4.pdf

Fundación para la Justicia y el Estado Democrático de Derechos y la Casa del Migrante de Saltillo (06 de junio de 2014). Tribunal colegiado confirma admisión de amparo contra CNDH en el caso de la masacre de 72 migrantes en San Fernando. México: Fundación para la Justicia. Recuperado de: http://www.fundacionjusticia.org/wp-content/ uploads/20I4/06/Comunicado-Juez-desecha-queja-dela-CNDH-en-contra-de-amparo-72-migrantes.pdf

González, L. (I8 de noviembre de 20 I4). Mensaje del Licenciado Luis Raúl González Pérez, con motivo del inicio de su gestión como Presidente de la CNDH. Recuperado de: http://www.cndh.org.mx/sites/all/fuentes/documentos/ Discurso/2014III8.pdf 
Bibliografía
Human Rights Watch (2008). La Comisión Nacional de los Derechos Humanos en México. Una evaluación crítica. México: HRW. Recuperado de: http://www.hrw.org/ es/reports/2008/02/I2/la-comisi-n-nacional-de-losderechos-humanos-de-m-xico-0

International Council on Human Rights Policy (2000). Desempeño y Legitimidad: Instituciones Nacionales de Derechos Humanos. Resumen de resultados. Ginebra: ICHRP. ISBN 2-940259-07-0. Recuperado de: http://www.ichrp.org/ files/summaries/36/102_summary_es.pdf

International Council on Human Rights Policy (2005). Evaluar la Eficacia de las Instituciones Nacionales de Derechos Humanos. Ginebra: Consejo Internacional para Estudios de Derechos Humanos. Recuperado de: http://www. ichrp.org/files/reports/20/I25_report_es.pdf

La Jornada Michoacán (23 de mayo de 20I4)."ONG refuta a la CEDH: en lo que va del año se han registrado 50 desapariciones". Recuperado de: http://www.lajornadamichoacan.com.mx/20 I4/05/23/ong-refuta-a-la-cedh-enlo-que-va-del-ano-se-han-registrado-50-desapariciones Lachenal, C.; Martínez,J.y Moguel, M. (2009). Los organismos públicos de derechos humanos en México. Nuevas instituciones, viejas prácticas. México: Fundar Centro de Análisis e Investigación, A.C.

Martínez, E. (23 de junio del 20I4). "Inicia CNTE en Michoacán paro de 3 días; exigen mejoras salariales". La Jornada. Recuperado de: http://www.jornada.unam. $\mathrm{mx} /$ ultimas/20 I 4/06/23/inicia-cnte-en-michoacan-parode-3-dias-exigen-mejoras-salariales- $|3| 2$.html

Méndez, E. (04 de noviembre de 2013).“Insuficiente, el gasto a derechos humanos; tareas de la CNDH aumentaron: diputados". La Jornada. Recuperado de: http://www. jornada.unam.mx/20 I3/ I l/04/politica/0 I 2n I pol

Noticias MVS (22 de julio de 20I4). "Persisten riesgos en el ejercicio del periodismo en México; Veracruz el 
lugar más peligroso: ONG's". Recuperado de: http:// noticiasmvs.com/\#!/noticias/persisten-riesgos-en-elejercicio-del-periodismo-en-mexico-veracruz-el-lugarmas-peligroso-ongs-439.html

Obrajero, J. (I8 de agosto de 20I4). "Arremeten ONG's contra CNDH en foro de San Lázaro”. W Radio. Recuperado de: http://www.wradio.com.mx/noticias/actualidad/arremeten-ongs-contra-cndh-en-foro-de-sanlazaro/20 I408I8/nota/2373080.aspx

Periodismo Electrónico (20I4). "Grave problema de feminicidios en Chihuahua". Recuperado de: http://www. periodismoelectronico.com/informacion-historicanotas-chihuahua/2988-grave-problema-de-feminicidiosen-chihuahua.html

Ramírez, A. (I0 de agosto de 20 I4). "Velan por los derechos humanos de los migrantes". Milenio Jalisco. Recuperado de: http://www.milenio.com/jalisco/Velan-derechos-humanos-migrantes_0_35I564884.html?utm_ source=Facebook\&utm_medium =Referral\&utm term $=$ Region \&utm_content=Foto\&utm campaign=MilenioDiariojalisco

Red Nacional de Organismos Civiles de Derechos Humanos Todos los Derechos para todas y todos (4 de marzo de 2013). "Informe Conjunto presentado por organizaciones de la sociedad civil mexicana para la segunda ronda del Examen Periódico Universal de México". Recuperado de: http://www.iccnow.org/documents/ Informe_conjunto_presentado_por_organizaciones_ de_la_sociedad_civil_mexicana.pdf

Redacción Unión Jalisco (I4 de mayo de 20I4). "Destino de Álvarez Cibrián, en manos de la SCJN". Recuperado de: http://www.unionjalisco.mx/articulo/20|4/05/I4/ gobierno/guadalajara/destino-de-alvarez-cibrian-enmanos-de-la-scjn 
Bibliografía
Saldierna G.y Méndez E. (25 de septiembre de 20I4).“Dan entrada en San Lázaro a solicitud de juicio político contra el titular de la CNDH". La Jornada. Recuperado de: http://www.jornada.unam.mx/20 |4/09/25/ politica/006n I pol

Sánchez Susarrey, J. (5 de abril de 20I4). "La corrupción y complicidad de las autoridades en Michoacán”. Grupo Reforma. Recuperado de: http://www.seguridadjusticiaypaz.org.mx/temas-de-interes/impunidad/990la-corrupcion-y-complicidad-de-las-autoridades-enmichoacan

Tlachinollan Centro de Derechos Humanos de La Montaña (20I3). Digna Rebeldía: Guerrero el epicentro de las luchas de resistencia. Guerrero: Tlachinollan. Recuperado de: http://www.tlachinollan.org/wp-content/ uploads/20 I4/I0/I9-INFORME_TLACHINOLLAN.pdf 